\title{
Cell Death of Lumbosacral Motoneurons in Chick, Quail, and Chick-Quail Chimera Embryos: A Test of the Quantitative Matching Hypothesis of Neuronal Cell Death
}

\author{
Hideaki Tanaka ${ }^{1}$ and Lynn T. Landmesser \\ Department of Physiology and Neurobiology, The University of Connecticut, Storrs, Connecticut 06268
}

\begin{abstract}
The quantitative matching hypothesis of neuronal cell death was tested for the chick hindlimb by determining the relationship between myotube number at the onset of motoneuron cell death and the number of motoneurons that survive in chicks, quail, and chick-quail chimeras. Hindlimb buds, which differ in size between the 2 species, were exchanged at stages $161 / 2-$ 19, myosin ATPase-stained myotubes in selected thigh muscles were counted during the cell death period (stages 30-34), and lumbosacral motoneurons were counted following the cell death period (stage 38 ).
\end{abstract}

No quail motoneurons were rescued when quail cords innervated chick limbs. When chick cords innervated quail limbs, the number of surviving motoneurons was significantly decreased but not to quail values. We consider that this occurred because chicks develop more slowly than quail, and we found that transplanted chick limbs were developmentally younger than the contralateral quail limb at the onset of motoneuron cell death and contained fewer myotubes. Similarly, transplanted quail limbs contained more myotubes at the onset of cell death than normal stage 30 quail limbs. An excellent correlation was obtained during normal development of both species between the number of myotube clusters at the onset of cell death and the number of surviving motoneurons. This correlation was also observed for chick-quail chimeras, and when the data points were plotted for control chick, control quail, chick host-quail limb, and quail host-chick limb, the correlation coefficient was 0.996 . This strongly suggests that some parameter closely related to myotube number limits the number of motoneurons that will survive.

A proposal consistent with our observations is that motoneuron survival is dependent on the uptake of a myotube-derived trophic factor that can only be taken up at synaptic sites and that the number of such sites is limited and directly related to myotube number. In conclusion, our observations strongly support a quantitative-matching component in the process of neuronal cell death. However, since we were unable to rescue any neurons, we cannot exclude the possibility that some proportion of neurons normally dies for reasons other than peripheral competition.

\footnotetext{
Received Oct. 2, 1985; revised Mar. 10, 1986; accepted Mar. 17, 1986.

We thank Ralph Somes, Department of Nutritional Sciences, The University of Connecticut, for providing quail eggs, Sara Putnam for her secretarial support, Mary Jane Spring for help with the illustrations, and Guillermo Pilar, Lisa Dahm, and Steve Meriney for critical evaluation of the manuscript.

This work was supported by NIH Grant NS 19640 (L.T.L.). H.T. was supported by the foreign study program of the Japanese Ministry of Education, Science, and Culture and a fellowship from the Muscular Dystrophy Association.

Correspondence should be addressed to Lynn T. Landmesser, Department of Physiology and Neurobiology, Room 416, 75 North Eagleville Road, Storrs, CT 06268

'Present address: Department of Pharmacology, Gunma University School of Medicine, Maebashi 371, Japan.

Copyright (C) 1986 Society for Neuroscience $0270-6474 / 86 / 102889-11 \$ 02.00 / 0$
}

Naturally occurring neuronal cell death is a well-described phenomenon common to many parts of the developing nervous system (for reviews, see Cowan et al., 1984; Cunningham, 1982; Hamburger and Oppenheim, 1982; Lamb, 1984; Oppenheim, 1981). In many vertebrate species, approximately half of the motoneurons in the lumbar lateral motor column die during a short span of time called the cell death period-embryonic days (E) 6-9 in the chick (Hamburger, 1975; Lamb, 1981a; LanceJones, 1982; Oppenheim et al., 1978). The extent of motoneuron cell death can be modified by the target; almost all of the motoneurons die after limb ablation (Hamburger, 1958; Lamb, 1981a; Oppenheim et al., 1978; Prestige, 1967) or in a limbless mutant chick (Lanser and Fallon, 1984), whereas the addition of a supernumerary limb increases the number of surviving motoneurons by about 10-30\% (Hollyday and Hamburger, 1976). These results support the idea that neuronal cell death is a process to properly match the size of a neuronal population to the size of its postsynaptic target (Hamburger, 1975; Hamburger and Oppenheim, 1982). Additional support for this hypothesis is derived from the observation that the post-cell death number of chick motoneurons is closely correlated with the number of their target myotubes during the period of cell death (McLennan, 1982).

If cell death is due solely to an inadequate amount of target, as some have suggested, it should be possible to prevent cell death by sufficiently increasing the target size. However, experiments in which target size was approximately doubled resulted in rescue of only about $50 \%$ or less of the motoneurons that would normally die (Boydston and Sohal, 1979; Hollyday and Hamburger, 1976; Hollyday and Mendell, 1976; Narayanan and Narayanan, 1978). A similar degree of rescue (i.e., approximately $40 \%$ ) was found in the ciliary ganglion when the neuronal population was decreased by more than half (Pilar et al., 1980). In contrast, when embryos were chronically exposed to neuromuscular blocking agents (Creazo and Sohal, 1979; Laing, 1982; Pitman and Oppenheim, 1978, 1979) or GMP (Weill and Greene, 1984), motoneuron cell death was dramatically, and in some cases completely, prevented. These experiments indicate that motoneurons are not inevitably programmed to die, but that the regulation of cell death may be more complex than previously considered.

An alternative explanation for cell death is that it is a means for removing neurons that have failed to establish appropriate connections (Lamb, 1979, 1980). Although Lamb (1979, 1980, $1981 \mathrm{a}, \mathrm{b})$ has presented some evidence supporting this hypothesis (see also Laing, 1982), it is also apparent that many neurons establish peripheral projections with considerable precision (Farel and Bemelmans, 1985; Hollyday, 1983; Lance-Jones and Landmesser, 1981a; Landmesser, 1978), that wrongly projecting motoneurons do not inevitably die (Hollyday, 1981; Lance-Jones and Landmesser, 1981b; Landmesser and O'Donovan, 1984; Straznicky, 1983; Summerbell and Stirling, 1981) and that ini- 
tially diffuse projections may be made more precise by collateral retraction rather than by cell death (O'Leary et al., 1981).

When attempting to place these sometimes conflicting observations in context, it is important to recognize that a complicating feature of most experimental paradigms to double target size is that many motoneurons will innervate foreign targets, as is true of supernumerary limbs (Hollyday, 1981; Morris, 1978). In addition, although the control limbs in such animals are innervated by a subset of the normal spinal nerves, these nerves may preferentially innervate their original targets. Thus, their effective peripheral target may be less than what is apparent.

One way to avoid these difficulties is to cause motoneurons to innervate targets that are smaller or larger than normal, but of the same specificity. Limb transplants between the closely related avian species of chick and quail seemed ideal because although quail have significantly smaller limbs than chicks, their muscles are selectively innervated by homologous chick motoneurons (Tanaka and Landmesser, 1986). Thus, in the present study we have examined lumbosacral motoneuron cell death in chicks, quails, and chick-quail chimeras, and have correlated this with myotube number. We found that, for the quail, both the number of motoneurons and the number of myotube clusters at the end of the cell death period were approximately half the chick value. In addition, there was a good correlation between the number of motoneurons and the number of myotube clusters in chick-quail chimeras. Our results therefore appear to support the quantitative matching hypothesis of cell death. A brief report of these findings has appeared elsewhere (Tanaka and Landmesser, 1984).

\section{Materials and Methods}

\section{Embryonic surgery}

Fertile eggs from white Leghorn chicks and Japanese quail were incubated in a forced-draft incubator at $38^{\circ} \mathrm{C}$. At stages $16-19$, as defined by Hamburger and Hamilton (1951), and using the same criteria for quail embryos, embryonic surgery was performed on 203 embryos (98 chick host, 105 quail host) as previously described (Tanaka and Landmesser, 1986). Briefly, a right limb bud of either chick or quail was transplanted to the right side of an embryo of opposite species, whose right limb bud had been previously removed. Of these embryos, 76 (34 chick host, 42 quail host) survived to stages $25-38$ and had essentially normal limbs. Forty-five embryos were used in this study; the remainder were used in the study reported in the preceding article (Tanaka and Landmesser, 1986).

\section{Motoneuron counting}

Control chicks and quails at stages 29,38 , and 42 , and chick-quail chimeras at stages $36-371 / 2$ were decapitated, eviscerated, and the lumbar spinal cords were fixed in Bouin's solution, dehydrated in a graded series of ethanol, and embedded in paraffin. Serial 10- $\mu$ m-thick sections were stained with hematoxylin, celestin blue, and eosin-orange. Counts were made on every 6th (stages 29 and 38) or 10th (E16) section at $\times 630$ (stages 29 and 38 ) or $\times 400$ (E16). At stage 29 all profiles, and at stage 38 and 42 only large cell profiles, which contained a nucleus and were located in the lateral motor column (LMC), were counted. Total numbers of motoneurons were corrected according to the modified method of Abercrombie (1946) (Smolen et al., 1983). The rostral and caudal ends of the lateral motor column were determined by the midpoints between the last thoracic and first lumbosacral (LS 1) spinal ganglia and between LS 7 and 8 (quail) or LS 8 and 9 (chick).

\section{Myotube cluster counting}

Embryonic limbs from stage 30-34 embryos were frozen in a mixture of 2-methylbutane and dry ice and $15 \mu \mathrm{m}$ serial cross sections of the thigh were made. In all cases, including the chimeras, the stage was taken as that of the stage of the host embryo. The sections were stained for ATPase (Guth and Samaha, 1970; McLennan, 1983a). Sections were preincubated in acidic ( $\mathrm{pH} \mathrm{5.0)}$ buffer for $30 \mathrm{~min}$, incubated in a reaction mixture containing $2.7 \mathrm{mM}$ ATP, $50 \mathrm{mM} \mathrm{KCl}, 18 \mathrm{mM} \mathrm{CaCl}_{2}$, and 50 mm Sigma \#221 alkaline buffer for $2 \mathrm{hr}$ at $37^{\circ} \mathrm{C}$ with a change to fresh solution after $1 \mathrm{hr}$, and subsequently in $1 \% \mathrm{CaCl}_{2}$, followed by $1 \%$ ammonium sulfide. The number of myotubes within several predominately slow (sartorius, external adductor), predominately fast (internal adductor, posterior iliotibialis), and mixed (ischioflexorius, iliofibularis) muscles (McLennan, 1983a; M. Vogel and L. Landmesser, unpublished observations, 1986) were counted using camera lucida drawings of sections selected for the maximum width of each muscle in question.

A primary aim of the present study was to quantify the peripheral target available to motoneurons during the period of cell death. Although a number of parameters could conceivably have been quantified (including, for example, total volume), we chose to count myotube clusters for the following reasons. First, others have found a roughly 1:1 ratio between myotube clusters at the onset of cell death, and the number of surviving motoneurons in both chick limb (McLennan, 1982) and quail superior oblique muscle (Arumugam and Sohal, 1985). Further, it has recently been shown that motoneurons do not invade the developing hindlimb muscle masses until myotube formation occurs between stages 29-31; in fact, axon ramification within the target is temporally correlated with the formation of mature myotubes that express NCAM (neural cell adhesion molecule) on their cell surfaces (Tosney et al., 1986) and that stain for myosin ATPase (L. Landmesser, unpublished observations).

We counted myotube clusters rather than myotubes primarily for practical reasons. Briefly, during the cell death period, muscle cleavage in the avian limb has been completed, and individual muscles consist of clusters of muscle cells separated from each other by considerable extracellular space. Each cluster is formed by a single, large, more differentiated primary myotube, together with a variable number of closely assuciated differentiating myotubes and/or myoblasts (McLennan, 1982, 1983c; see also Arumugam and Sohal, 1985). Myotube clusters were easily distinguished, gave reproducible results, and were similar for a given muscle when counted at different proximal-distal levels. In contrast, the associated cells stained variably for myosin ATPase and also varied in number along the proximodistal axis, making them difficult to quantify. For example, in Figure 4, arrowheads point to profiles that we counted as single myotube clusters. We did not count the much smaller profiles (indicated by arrows) as these were seen only in the youngest limbs when primary myotube formation was still in progress, and they did not run the full length of the muscle. Thus, even though they stain for myosin ATPase, they appear to be myoblasts or muscle precursor cells. It should be stressed that we counted myotube clusters primarily because this appeared to be the most reproducible way of quantifying the peripheral target during the cell death period. The values we obtained were similar to those previously reported for the chick limb (McLennan, 1982), and the ratio of myotube clusters to surviving motoneurons that we obtained is similar to that reported by Arumugam and Sohal for the quail superior oblique muscle during a comparable developmental period.

\section{Results}

\section{Chick and quail embryos differ in size of lateral motor} column and thigh muscles

Chick and quail are closely related species whose homologous muscles exhibit similar spatial relationships. However, a cross section through the thigh at stage 34 (Fig. 1) reveals that the quail limb is considerably smaller than the chick, as are its component muscles. Figure 2 shows that the quail latcral motor column is similarly reduced when compared to the chick. To quantify these differences we made counts of the numbers of motoneurons and myotubes during the cell death period.

\section{Motoneuron cell death in control chick and quail embryos}

Motoneurons in the LMC were counted both before and after the cell death period (Fig. 3, Table 1). In the chick, the corrected means prior to cell death $(19,245$ at E6, stage 29) and after cell death (9409 at E12, stage 38) were similar to previously published values (Hamburger, 1975; Oppenheim et al., 1978). Using the same counting procedure, we found that quail motoneuron numbers were reduced sharply between E5 and E10 (stages 2938). A small number of cells were lost later between days 10 and 16, as occurs in the chick (Okado and Oppenheim, 1984). 

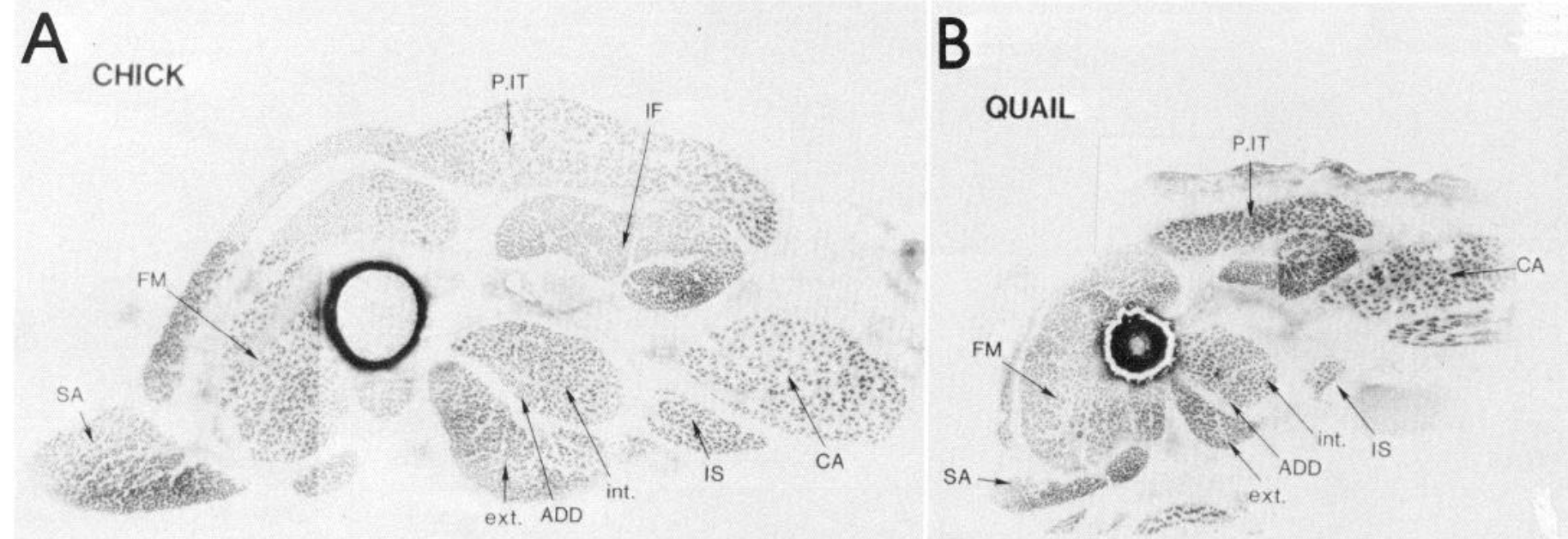

Figure 1. Transverse sections of chick $(A)$ and quail $(B)$ limbs at midthigh level stained with myosin ATPase at stage 34 . Both slow and fast fibers are stained after preincubation at $\mathrm{pH}$ 5.0. The chick limb is clearly larger than the quail. Dark spots represent a single or a small cluster of myotubes. $S A$, sartorius; $F M$, femorotibialis; $P$. $I T$, posterior iliotibialis; $I F$, iliofibularis; $I S$, ischioflexorius; int (internal) and $e x t$ (external) $A D D$, adductor; $C A$, caudilioflexiolius. $\times 73$.

The quail motoneuron cell death period thus occurs during the same embryonic stages as does the chick. Both before (stage 29) and after (stage 38) the cell death period, quail motoneurons numbered only about half the chick value. The ratio of surviving motoneurons in both species was quite similar, $48.9 \%$ (chick) and $50.5 \%$ (quail). At these stages, there were no significant differences in size between chick and quail motoneurons. Thus, in both quail and chick, about twice as many motoneurons are produced as ultimately survive.

\section{Motoneuron cell death in chick-quail chimeras}

To examine the effects of target size on motoneuron cell death, chick-quail chimeras were used to change the target size without altering selective innervation of individual muscles (see preceding paper, Tanaka and Landmesser, 1986). We counted the motoneurons in the LMC of chick-quail chimeras after the cell death period and reasoned that if motoneuron cell death were involved solely in achieving selective innervation (Lamb, 1979, $1980,1981 \mathrm{a}, \mathrm{b})$ motoneuron numbers would not be altered when a lateral motor column innervated a limb of different size. Alternatively, if the quantitative matching hypothesis held, we would expect that the chick motoneurons innervating a quail limb would be reduced to approximately half the control number. Similarly, based on control values in both species, quail motoneuron cell death should be decreased by approximately $75 \%$ following innervation of a chick limb.

We found that for the chick host, the mean number of motoneurons on the side innervating the quail limb was significantly reduced ( 8106 transplant side vs 10,041 host side) but not to control quail values (5652). When quail cords innervated chick limbs, motoneuron numbers were not significantly altered (4454 transplant side vs 5771 host side; Mann-Whitney test; see Table 2).

These results do not appear to support either hypothesis of cell death. For example, no quail motoneurons were rescued when they innervated the apparently larger chick limbs. However, we also noticed that the transplanted chick limbs were not larger and were, in fact, often smaller than the contralateral quail host limbs. Based on Hamburger and Hamilton staging criteria, we found that these limbs were also developmentally younger than the contralateral quail limbs. This was presumably due to the slightly different rates of development in the 2 species; chicks hatching after $21 \mathrm{~d}$, quail after only 18 . In fact, by stages 34 38 , control chicks incubated at the same time as the transplant

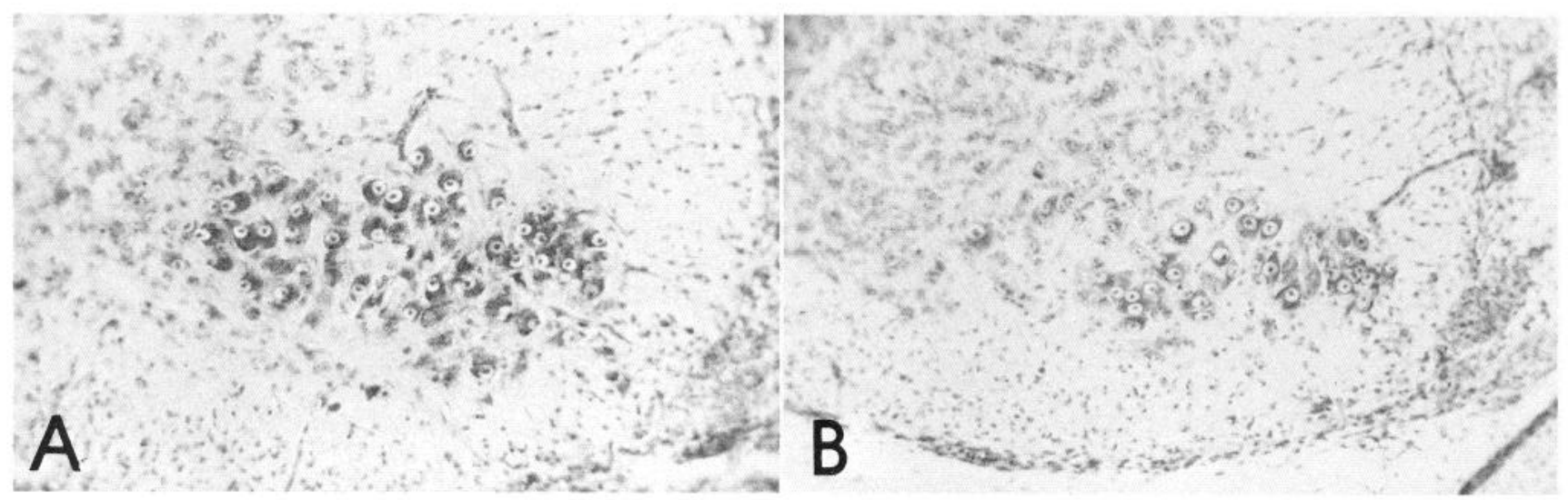

Figure 2. Transverse sections of chick $(A)$ and quail $(B)$ cords at stage 38 . Motoneurons in the LMC are clearly distinguished by their large size and darkly stained cytoplasm. $\times 220$. 


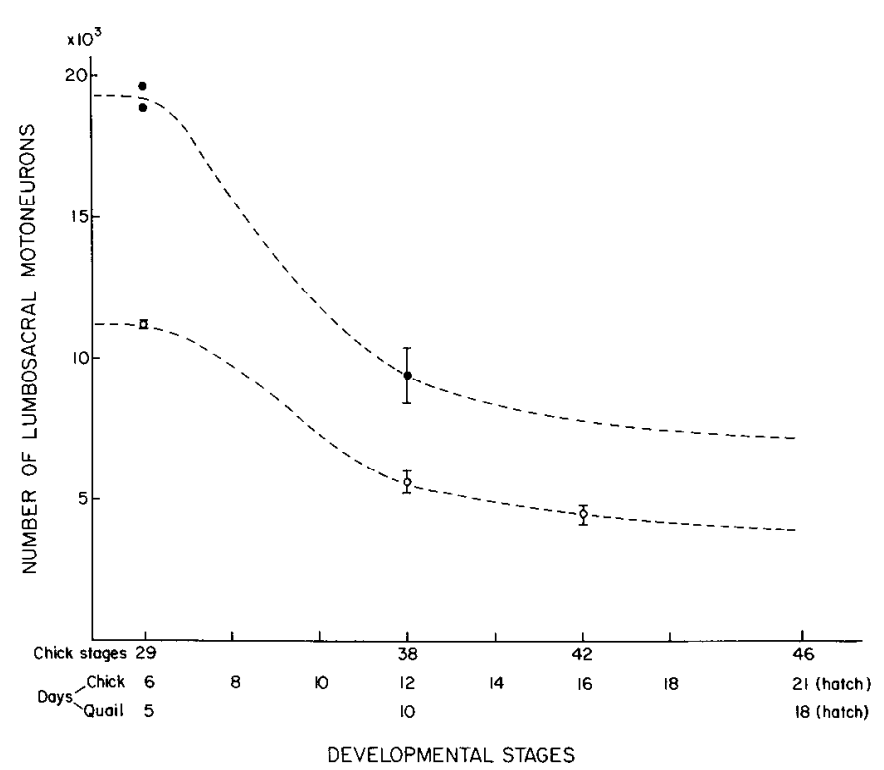

Figure 3. Changes in numbers of motoneurons in the chick (filled circles) and quail (open circles) LMCs (means \pm SD). Developmental rates are slightly different between chick and quail, chicks hatching after $21 \mathrm{~d}$ incubations and quails after $18 \mathrm{~d}$.

donors were found to be 1-3 stages younger than quail similarly incubated. Furthermore, the transplanted quail limbs were found to be developmentally older than the host chick limbs.

In Figure 4, cross sections at the thigh level, stained for myosin ATPase, are shown for 2 chick-quail chimeras. It can be seen that the muscles of the transplanted quail limb (Fig. $4 B$ ) are as well formed as those in the chick host limb (stage 30; Fig. 4A) but are at a more mature developmental stage. For example, although many of the primary myotubes are small and stain only weakly for ATPase in the chick limb (for example, in the internal and external adductor shown at higher magnification in Fig. 4C), they are well developed in the quail limb (Fig. $4 D$ ). Similarly, in a quail host, the chick adductor (Fig. $4 E$ ) can be seen by the same criteria to be younger than the host quail adductor (Fig. $4 F$ ). In addition, the 2 heads of the adductor are more fully cleaved in the more "mature" limbs (Fig. $4, D, F$ ) than in the "younger" limbs (Fig. 4, C,E). Such differences in developmental stage were also apparent when using feather germ or digit development to stage the limbs.

We excluded the possibility that motoneuron numbers might be less than expected in donor limbs because of some direct effect of the operation. We found that when a chick limb was removed and replaced or placed onto a second chick embryo, neither the stage of the limb nor post-cell death motoneuron numbers differed from control values (Table 2 ). This was also found in earlier studies when chick limbs were rotated about the anterior-posterior axis (Landmesser and O'Donovan, 1984).

These observations suggested that transplanted limbs developed according to their innate schedule and that this might cause transplanted limbs to be smaller or larger than the control host limbs during the cell death period. This in turn may have contributed to the unexpected results we obtained on motoneuron numbers. This possibility was supported by myotube counts.

\section{Number of myotube clusters in chick-quail chimeras and control embryos}

The number of myotube clusters in various chick hindlimb muscles during the cell death period has been shown to be closely correlated with the numbers of motoneurons that innervate them at the end of the cell death period (McLennan, 1982). Therefore,
Table 1. Cell counts of motoneurons in the lumbar LMC

\begin{tabular}{llllll}
$\begin{array}{l}\text { Ani- } \\
\text { mals }\end{array}$ & Stage & Raw counts & $\begin{array}{l}\text { Correc- } \\
\text { tion } \\
\text { factor }\end{array}$ & \multicolumn{1}{l}{$\begin{array}{l}\text { Corrected } \\
\text { counts }\end{array}$} & $n$ \\
\hline Chick & 29 & $26,007 \pm 573$ & 0.74 & $19,245 \pm 424$ & 2 \\
& 38 & $14,702 \pm 1532$ & 0.64 & $9409 \pm 980$ & 4 \\
\multirow{4}{*}{ Quail } & 29 & $15,127 \pm 186$ & 0.74 & $11,194 \pm 138$ & 4 \\
& 38 & $8074 \pm 536$ & 0.70 & $5652 \pm 375$ & 6 \\
& 42 & $6473 \pm 489$ & 0.70 & $4531 \pm 342$ & 4 \\
\hline
\end{tabular}

we counted myotubes to examine the correlation between postcell death motoneuron numbers and the target size. Following myosin ATPase histochemistry, myotube clusters are clearly defined and easily counted (Fig. 4). However, individual myotubes were difficult to distinguish, so we chose to quantify the target size by counting myotube clusters [arrowheads in Fig. 4, $C, E$; other small stained profiles (arrows) were not counted] for many of the major thigh muscles: sartorius, adductor, ischioflexorius, iliofibularis, and posterior iliotibialis. We selected predominantly slow (sartorius, external adductor), predominantly fast (internal adductor, posterior iliotibialis), and mixed (ischioflexorius, iliofibularis) muscles. Distributions of fast and slow fibers in chick and quail muscles were similar with only minor exceptions. For example, the quail sartorius has more fast fibers than chick.

Counts were made in host embryos ranging between stages 30 and 34 for several reasons. First, this was done during the cell death period when target size would be expected to have its most important effect if it is indeed a factor in regulating cell death. Second, it has been shown that myotube formation at these stages is autonomous and not dependent on innervation (Harris, 1981; McLcnnan, 1983c; Phillips and Bennett, 1984), whereas at later stages, secondary myotube formation requires innervation, and uninnervated primary myotubes atrophy and die. The numbers of myotube clusters in most muscles gradually increased between stages $30-34$ in both chick and quail. There were no significant differences in development among different muscles. The ratios of the total number of myotube clusters at stage 34 to those at stage 30 were very similar for chick and quail: 2.48 and 2.62 , respectively (Table 3 ). Chicks contained more myotubes at both stages, the ratio of chick to quail being 2.19 at stage 30 and 2.08 at stage 34 . These results show that in both chick and quail, myotube numbers increase to approximately the same extent during the cell death period, somewhat more than doubling.

The number of myotube clusters in chimeras is shown in Tables 4 and 5. Since we averaged myotube numbers between stages 30 and 33 , for both quail and chick the host values are somewhat larger than the stage 30 control values for the same species (Table 3 ). However, it is readily apparent that the transplanted quail limbs (staged on the basis of the host chick embryo) contain more myotubes than similarly staged quail hosts, also shown in Tables 4 and 5 . This supports the idea that transplanted quail limbs were developmentally older than the control limbs at the time of sacrifice of the host chick embryo. Similarly, transplanted chick limbs on quail hosts contained considerably fewer myotubes than the contralateral control quail limb or than quail limbs from unoperated stage 30 embryos, and were apparently developmentally younger.

We were unable to correct for this age disparity at the onset of cell death by intentionally placing older limbs on younger embryos. We found that the maximal age disparity at the time of surgery compatible with the development of normally formed and successfully innervated donor limbs did not appreciably 




Figure 4. Myosin ATPase staining of the thigh muscles in chick host chimera $(A-D)$ and quail host $(E, F)$. A stage 19 quail limb was transplanted onto a stage 18 chick embryo. Four days later, when the host chick was at stage 30 , both limbs were sectioned and stained $(A-D)$. The transplanted quail limb $(B)$ developed as well as the host chick limb $(A)$. In fact, based on feather germ and digit development, it was older than the chick limb. Supporting this, it was only slightly smaller than the chick limb. In addition, the chick host adductor $(C)$ had many small, differentiating, primary myotubes (arrows), whereas the myotubes were more mature in the transplanted quail adductor $(D)$. (In $D$ the muscles have been photographically reversed from $B$. The asterisk indicates the same position in both figures.) Similarly, when a chick limb was transplanted onto a quail host, the transplanted chick adductor $(E)$ was less mature than the host quail adductor (i.e., it contained more smaller immature myotubes and the 2 heads were less fully cleaved). It is, in fact, quite similar in appearance to the stage 30 chick limb $(A, C)$, although the quail host in this case was stage $33(F)$. In this case, a stage $18 \frac{1}{2}$ chick limb was transplanted onto a stage 19 quail, and the muscles stained when the host quail was at stage 33 . $A$ and $B, \times 40 ; C-F, \times 130$.

alter the age of the limb at the onset of cell death (stage 30). The possibility of using a different species, Bobwhite quail, which has a longer incubation period than the chick, was also explored. However, preliminary counts of the number of myotubes in comparable Bobwhite thigh muscles at stage 30-31 produced values of $1441 \pm 98$ compared to $1551 \pm 278$ for the chick. Therefore, we would have expected at best only a modest rescue of Bobwhite quail motoneurons following innervation of a chick limb, and we did not pursue this line of experimentation further.

Nevertheless, from the standpoint of testing the quantitative 
Table 2. Cell counts of motoneurons in the lumbar LMC of chick-quail chimeras

\begin{tabular}{|c|c|c|c|c|c|c|}
\hline \multirow[b]{2}{*}{ Animals } & \multirow{2}{*}{$\begin{array}{l}\text { Stages } \\
\text { fixed }\end{array}$} & \multicolumn{2}{|c|}{ Stages operated } & \multirow[b]{2}{*}{ Host side } & \multirow[b]{2}{*}{ Operated side } & \multirow{2}{*}{$\begin{array}{l}\text { Diffcr- } \\
\text { ence } \\
(\%)\end{array}$} \\
\hline & & Host & Donor & & & \\
\hline \multicolumn{7}{|c|}{ Chick host } \\
\hline 1 & 36 & 18 & 19 & 15,471 & 12,398 & -20 \\
\hline 2 & 36 & $181 / 2$ & $181 / 2$ & 17,837 & 14,008 & -21 \\
\hline 3 & $361 / 2$ & $171 / 2$ & $171 / 2$ & 15,444 & 14,058 & -9 \\
\hline 4 & $36^{1 / 2}$ & 18 & $181 / 2$ & 16,787 & 12,212 & -27 \\
\hline 5 & $371 / 2$ & 17 & 19 & 12,904 & 10,656 & -17 \\
\hline \multirow{2}{*}{\multicolumn{4}{|c|}{$\begin{array}{l}\text { Mcan } \pm \mathrm{SD} \\
\text { Corrected mean } \pm \mathrm{SD}\end{array}$}} & $15,689 \pm 1850$ & $12,666 \pm 1419$ & \\
\hline & & & & $10,041 \pm 1184$ & $8106 \pm 908^{a}$ & -19 \\
\hline \multicolumn{7}{|c|}{ Quail host } \\
\hline 1 & 36 & $171 / 2$ & $181 / 2$ & 10,235 & 7720 & -25 \\
\hline 2 & 36 & 17 & 19 & 7642 & 6379 & -12 \\
\hline 3 & $361 / 2$ & $161 / 2$ & 17 & 8513 & 6984 & -18 \\
\hline 4 & 37 & $181 / 2$ & $18 \frac{1}{2}$ & 8450 & 5604 & -34 \\
\hline 5 & 37 & 17 & 19 & 6378 & 4768 & -25 \\
\hline \multirow{2}{*}{\multicolumn{4}{|c|}{$\begin{array}{l}\text { Mean } \pm \mathrm{SD} \\
\text { Corrected mean } \pm \mathrm{SD}\end{array}$}} & $8244 \pm 1407$ & $6363 \pm 1171$ & \\
\hline & & & & $5771 \pm 985$ & $4454 \pm 820^{b}$ & -23 \\
\hline \multicolumn{7}{|c|}{ Control (chick host-chick donor) } \\
\hline 1 & 37 & 18 & 18 & 13,292 & 12,992 & -2 \\
\hline 2 & 36 & 18 & 18 & 15,053 & 15,019 & 0 \\
\hline
\end{tabular}

matching hypothesis, the most meaningful comparison is the ratio of myotube numbers at the time of cell death to the numbers of motoneurons that ultimately survive. In Figure 5, the mean number of myotubes for each of the 4 cases (chick hostchick limb, chick host-quail limb, quail host-quail limb, and quail host-chick limb) is plotted against the mean post-cell death number of motoneurons for each case. It can be seen that there is an excellent correlation, the correlation coefficient being 0.996 . Thus, there is a significant correlation $(p<0.01)$ between the number of myotube clusters during the motoneuron cell death period and the final, post-cell death number of motoneurons.

McLennan (1982) found a roughly $1: 1$ ratio between the number of myotube clusters during the motoneuron cell death period and the number of surviving motoneurons. We did not count all myotubes in the limb and, instead, compared the relationship between myotube number from a representative group of mus- cles to the total number of motoneurons. Nevertheless, a comparison of myotube cluster values for individual muscles with previously published values for their motoneuron pools (Landmesser, 1978) indicates a myotube/motoneuron ratio of between 1 and 2 . We found that for predominately fast muscles the ratio was closer to 1 (posterior iliotibialis, 1.18; caudilioflexorius, 1.04), whereas for muscles that were predominately slow at the onset of motoneuron cell death, the ratio was closer to 2 (sartorius, 1.90; iliofibularis, 1.78; femorotibialis, 1.78). Thus, the overall ratio would be expected to fall somewhere between 1 and 2 . A close to 1:1 ratio has also been reported for the duck superior oblique muscle (Arumugam and Sohal, 1985).

\section{Discussion}

One of the most widely accepted explanations for naturally occurring cell death is that it serves to match the size of a neuronal

Table 3. Numbers of myotube clusters in chick and quail thigh muscles

\begin{tabular}{|c|c|c|c|c|c|c|c|c|}
\hline \multirow[b]{2}{*}{ Muscles } & \multicolumn{3}{|l|}{ Chick } & \multicolumn{3}{|l|}{ Quail } & \multicolumn{2}{|c|}{$\begin{array}{l}\text { Chick stage/ } \\
\text { quail stage }\end{array}$} \\
\hline & Stage 30 & Stage 34 & $\begin{array}{l}\text { Stage } \\
34 / 30\end{array}$ & Stage 30 & Stage 34 & $\begin{array}{l}\text { Stage } \\
34 / 30\end{array}$ & $\begin{array}{l}\text { Stage } \\
30 / 30\end{array}$ & $\begin{array}{l}\text { Stage } \\
34 / 34\end{array}$ \\
\hline Sartorius & $338 \pm 60$ & $709 \pm 93$ & 2.10 & $132 \pm 27$ & $251 \pm 26$ & 1.90 & 2.56 & 2.82 \\
\hline \multicolumn{9}{|l|}{ Adductor } \\
\hline Internal & $181 \pm 39$ & $406 \pm 39$ & 2.24 & $126 \pm 16$ & $286 \pm 5$ & 2.27 & 1.44 & 1.42 \\
\hline External & $257 \pm 69$ & $759 \pm 128$ & 2.95 & $84 \pm 26$ & $303 \pm 24$ & 3.61 & 3.06 & 2.50 \\
\hline Ischioflexorius & $120 \pm 26$ & $271 \pm 44$ & 2.26 & $54 \pm 16$ & $60 \pm 5$ & 1.11 & 2.22 & 4.52 \\
\hline P. iliotibialis & $202 \pm 40$ & $572 \pm 151$ & 2.83 & $149 \pm 42$ & $427 \pm 16$ & 2.87 & 1.36 & 1.34 \\
\hline Iliofibularis & $374 \pm 65$ & $933 \pm 76$ & 2.49 & $127 \pm 28$ & $432 \pm 33$ & 3.40 & 2.94 & 2.16 \\
\hline Total & $1473 \pm 249$ & $3648 \pm 434$ & 2.48 & $671 \pm 101$ & $1759 \pm 93$ & 2.62 & 2.19 & 2.08 \\
\hline
\end{tabular}


Table 4. Numbers of myotube clusters in chick-quail chimera thigh muscles

\begin{tabular}{lcclllll} 
& Chick host & & & & Quail host \\
\cline { 2 - 3 } Muscles & $\begin{array}{l}\text { Host chick } \\
\text { limb }\end{array}$ & $\begin{array}{l}\text { Transplanted } \\
\text { quail limb }\end{array}$ & $\begin{array}{l}\text { Quail } \\
\text { chick }\end{array}$ & & $\begin{array}{l}\text { Host quail } \\
\text { limb }\end{array}$ & $\begin{array}{l}\text { Transplanted } \\
\text { chick limb }\end{array}$ & $\begin{array}{l}\text { Chick/ } \\
\text { Quail }\end{array}$ \\
\hline $\begin{array}{l}\text { Sartorius } \\
\text { Adductor }\end{array}$ & $345 \pm 57$ & $205 \pm 34$ & 0.59 & $172 \pm 24$ & $164 \pm 12$ & 0.95 \\
$\quad$ Internal & $191 \pm 41$ & $215 \pm 75$ & 1.13 & $162 \pm 45$ & $131 \pm 53$ & 0.81 \\
$\quad$ External & $272 \pm 67$ & $164 \pm 63$ & 0.60 & $129 \pm 50$ & $115 \pm 52$ & 0.89 \\
Ischioflexorius & $130 \pm 24$ & $44 \pm 10$ & 0.34 & $50 \pm 8$ & $87 \pm 18$ & 1.74 \\
P. iliotibialis & $236 \pm 63$ & $202 \pm 80$ & 0.86 & $206 \pm 72$ & $164 \pm 30$ & 0.80 \\
Iliofibularis & $377 \pm 74$ & $245 \pm 87$ & 0.65 & $164 \pm 61$ & $124 \pm 53$ & 0.76 \\
Total & $1551 \pm 278^{a}$ & $1075 \pm 307^{a}$ & 0.69 & $883 \pm 220^{b}$ & $785 \pm 121^{b}$ & 0.89
\end{tabular}

Chick host ( $n=7$; host stages: $\left.30,30,30,31,31 \frac{1}{2}, 32 \frac{1}{2}, 32 \frac{1}{1} 2\right)$. Quail host $(n=6$; host stages: 301/2, 301/2, 31, 31, 32, 33). Means $\pm \mathrm{SD}$ are shown.

$p<0.01$.

${ }^{b} p>0.05$.

population to the size of its target (for reviews, see Cowan, 1973; Cunningham, 1982; Hamburger and Oppenheim, 1982; but see Lamb, 1984). In the PNS, complete early removal of a target results in death of almost all of the innervating neurons (Hamburger, 1958; Lamb, 1981a; Landmesser and Pilar, 1974; Oppenheim et al., 1978; Prestige, 1967), indicating that neurons need to interact with their targets to survive. However, these studies reveal little about the relevance of the size-matching hypothesis to normal development.

Less drastic reductions in the size of the target have provided support for the size-matching hypothesis. For example, Habgood et al. (1984) have recently shown that surgical reduction in the size of the mouse soleus muscle during the first few postnatal weeks results in a good correlation between the number of myofibers that remained and the number of surviving neurons. Their measure of dependency of motoneurons on the target (i.e., the fractional loss of motoneurons per fractional loss of muscle fibers) varied with age, being 0.8 during the first postnatal week. Although this is after the normal motoneuron cell death period (Lance-Jones, 1982), the dependency factor extrapolated back to the period of cell death was 1 .

Also consistent with the size-matching hypothesis, an increase in the size of a target rescues neurons, but the extent of rescue is generally less than one would predict from the increases in target size (Hollyday and Hamburger, 1976; Hollyday and Mendell, 1976). However, as discussed earlier (Pilar et al., 1980) and in the introduction, the interpretation of these results is complicated because many neurons in this situation will innervate foreign targets, and uniform innervation of the available target is unlikely to occur (Hollyday, 1981; Lance-Jones and Landmesser, 1981b; Morris, 1978). By using chick-quail chimeras we were able to circumvent this problem and make several observations that support the size-matching hypothesis.

First, we have extended the observations made by McLennan

Table 5. Total numbers of myotube clusters in thigh muscles of chick-quail chimeras

\begin{tabular}{|c|c|c|c|c|c|c|}
\hline \multirow[b]{2}{*}{ Animals } & \multirow{2}{*}{$\begin{array}{l}\text { Stages } \\
\text { examined }\end{array}$} & \multicolumn{2}{|c|}{ Stages operated } & \multirow[b]{2}{*}{ Host side } & \multirow[b]{2}{*}{ Operated side } & \multirow{2}{*}{$\begin{array}{l}\text { Differ- } \\
\text { ence } \\
(\%)\end{array}$} \\
\hline & & Host & Donor & & & \\
\hline \multicolumn{7}{|l|}{ Chick host } \\
\hline 1 & 30 & 18 & $191 / 2$ & 1257 & 661 & -47 \\
\hline 2 & 30 & 19 & 19 & 1269 & 1135 & -11 \\
\hline 3 & 30 & $191 / 2$ & $191 / 2$ & 1612 & 697 & -57 \\
\hline 4 & 31 & $19^{1 / 2}$ & 18 & 1832 & 1239 & -32 \\
\hline 5 & $31 \frac{1 / 2}{2}$ & $19^{1 / 2}$ & 18 & 1340 & 1049 & -22 \\
\hline 6 & $32 \frac{1}{2}$ & 18 & 19 & 1586 & 1221 & -23 \\
\hline 7 & $32^{1 / 2}$ & 18 & $171 / 2$ & 1962 & 1521 & -22 \\
\hline Mean \pm SD & & & & $1551 \pm 278$ & $1075 \pm 307$ & -31 \\
\hline \multicolumn{7}{|l|}{ Quail host } \\
\hline 1 & $301 / 2$ & $171 / 2$ & $171 / 2$ & 788 & 673 & -15 \\
\hline 2 & $301 / 2$ & $171 / 2$ & $171 / 2$ & 753 & 705 & -6 \\
\hline 3 & 31 & $181 / 2$ & 18 & 830 & 809 & -3 \\
\hline 4 & 31 & 18 & 19 & 928 & 671 & -28 \\
\hline 5 & 32 & $171 / 2$ & $18^{1 / 2}$ & 694 & 940 & +35 \\
\hline 6 & 33 & 19 & $181 / 2$ & 1302 & 914 & -30 \\
\hline Mean $\pm S D$ & & & & $883 \pm 220$ & $785 \pm 121$ & -8 \\
\hline
\end{tabular}


(1982) on the chick to a second species and have shown that for both species there is an excellent correlation between the number of myotubes at the time of cell death and the number of motoneurons that will eventually survive. In addition, this correlation was maintained in experimentally created chickquail chimeras. Taken together, these observations provide rather strong evidence for the size-matching hypothesis, and they suggest that some factor proportional to the number of myotube clusters may regulate cell death. A similar correlation has been found between the number of granule cells and the number of their target Purkinje cells when this number was genetically altered in chimeric Lurcher mice (Wetts and Herrup, 1983).

Unambiguous confirmation of the size-matching hypothesis would have been provided if we had been able to rescue approximately $75 \%$ of quail motoneurons by providing them with a chick limb containing a markedly increased number of myotubes. While we were unable to accomplish this, we consider the most tenable explanation for our failure to rescue any quail motoneurons, and for the survival of more motoneurons than expected when chick cords innervated quail limbs, to be that the transplanted limbs continued to develop according to their innate timetable. In fact, we found that transplanted chick limbs at the onset of cell death contained fewer myotubes than expected, whereas the converse was true of quail limbs. For this explanation to be valid, we would also expect that the onset of motoneuron cell death should occur according to the innate time schedule of the cord and not be delayed when quail cords innervated the younger chick limbs. Most of the chimeras studied at the onset of cell death were frozen for myosin ATPase staining of myotubes, so that the cords were unsuitable for motoneuron counting. Ilowever, in 1 quail host embryo, processed for Feulgen staining just after the onset of cell death (stage 30), we found that the number of motoneurons per section at 2 different levels of the lumbosacral enlargement did not differ significantly between the sides innervating the quail or chick limb $(56.6 \pm 6.1$ for the quail side vs $56.1 \pm 5.5$ for the chick side at LS 2 , and $66.4 \pm 8.3$ for the quail side and $71.9 \pm 7.7$ for the chick at LS 5 ). This suggests that the onset of cell death was not delayed on the side of the cord innervating the chick limb.

In contrast to these observations that appear to support the size-matching hypothesis, Spcrry and Grobstein (1985) failed to rescue any Xenopus motoneurons when they greatly increased the limb size by delaying metamorphosis with the thyroxine antagonist PTU. It should be noted that although the individual muscle fibers were considerably enlarged by the PTU treatment, the number of muscle fibers did not differ from control valucs. In an earlier study, Decker and Kollros (1969) were able to rescue Rana motoneurons when they created enlarged limbs by delaying metamorphosis by hypothermia. Unfortunately, in this case, muscle fiber number was not quantified.

Observations such as these emphasize the importance of determining what aspect of the target is actually involved in regulating motoneuron death. By analogy to NGF-sensitive neuron survival (for review, see Thoenen and Barde, 1980), developing myotubes may produce a trophic factor required by motoneurons during a critical period. In culture, chick motoneurons have been shown to require some substance derived from muscle (Nurcombe et al., 1984; Tanaka and Obata, 1983) and under the appropriate culture conditions, this requirement is age dependent, only becoming manifest at the time of cell death $(\mathrm{H}$. Tanaka, unpublished observations). The results of Sperry and Grobstein (1985) show that such a purported factor is not apparently available to motoneurons in direct proportion to muscle fiber volume. However, if under normal circumstances there are a limited number of synapses that can be made on each myotube, and if motoneurons are only able to take up adequate amounts of trophic substance from synapses, then one would expect a correlation between myotube number and the number

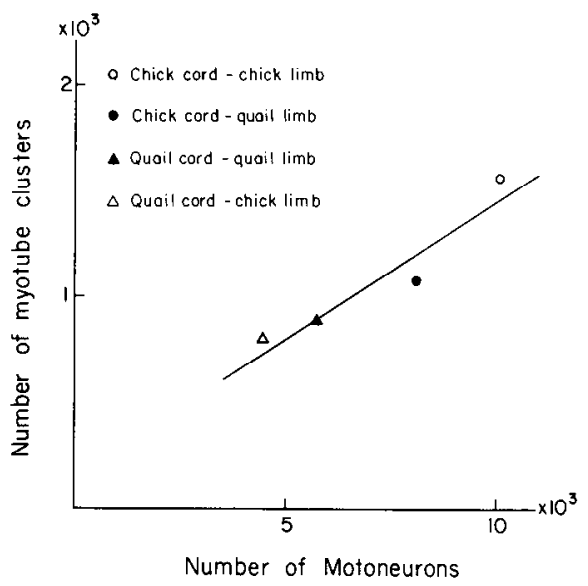

Figure 5. Mean number of myotube clusters during the cell death period plotted against the mean post-cell death number of motoneurons, and regression line was calculated for chick host-chick limb, chick hostquail limb, quail host-quail limb, and quail host-chick limb. The correlation coefficient $(r=0.996)$ indicates a highly significant correlation.

of surviving motoneurons, although not necessarily a 1:1 correlation. We have, in fact, found that the ratio appears to differ for predominately fast and predominately slow muscles.

This explanation is consistent with our own results and those of Sperry and Grobstein reported above. It is also consistent with several studies showing that motoneuron cell death can be prevented by blocking functional activity. Pittman and Oppenheim (1979) found that chronic application of neuromuscular blocking agents prevented chick motoneuron cell death. This treatment also prevents the formation of secondary myotubes, arresting myotube numbers to those present at the onset of cell death (McLennan, 1983c). However, such myotubes are hyperinnervated, i.e., there is an increased number of synaptic sites per muscle fiber (Oppenheim, 1984). Similar results were obtained by Harris and McCaig (1984), who blocked motoneuron cell death in mouse embryos by TTX application. This treatment also blocked the production of secondary myotubes, but since motor unit size was unaltered, these myotubes must also have been hyperinnervated. Thus, while inactivity may result in changes in muscle metabolism, including enhanced production of trophic factors, the number of synaptic sites per muscle fiber is also clearly increased. Taken together, these obscrvations suggest that the number of available synaptic sites may be the parameter that is actually regulating motoneuron number and that under normal conditions of activity this would be proportional to myotube number. In any case, these considerations clearly emphasize the need to quantify myotube number and other parameters dependent on it, such as the number of synaptic sites, at the time of motoneuron death. We are currently attempting to quantify synaptic sites by visualizing them through the combined use of a monoclonal antibody specific for nerve fibers and fluorescent-labeled $\alpha$-bungarotoxin to locate postsynaptic receptor clusters (L. Dahm and L. Landmesser, unpublished observations). At later stages, the number of muscle fibers may have been subsequently affected both by the level of activity (Harris and McCaig, 1984; McLennan, $1983 \mathrm{c}$ ), as well as the number of innervating neurons (Betz et al., 1980) and even hormone levels. Sohal and his coworkers have recently reported in experiments similar in design to our own (Sohal and Yamashita, 1985; see also Sohal et al., 1985) a failure to rescue any quail trochlear neurons when they innervated the larger duck trochlear muscles. To interpret this result as for or against the size-matching hypothesis, it will be necessary to quantify duck trochlear myotubes during the actual cell death period. 
A challenge to the size-matching hypothesis has been provided by Lamb's $(1980,1981$ b) observation that a single Xenopus limb could be innervated by both ipsi- and contralateral lateral motor columns and could support as much as double the normal complement of motoneurons. Although in a similar experimental paradigm, a single chick eye was unable to support increased cell numbers when innervated by 2 isthmo-optic nuclei (O'Leary and Cowan, 1984), taken at face value the observations of Lamb are in apparent conflict with a simple sizematching hypothesis. More recently, Lamb and his colleagues (Denton et al., 1985) have reported that in such dually innervated limbs, the number of synaptic sites per muscle fiber was not altered, at least at later stages, and that motor unit tensions were on average reduced. This indicates that the surviving motoneurons had made a smaller number of synapses than normal. They also reported preliminary evidence that muscle fiber number, again at later stages, was unchanged, but no data were presented. In this case, it is clearly important to determine myotube number and the number of synaptic sites at the time of the cell death period. If it proves to be the case that the number of myotubes and the number of synaptic sites during the cell death period are unaltered, it will be necessary to modify the size-matching hypothesis. Since activity (Thompson et al., 1979) and even the pattern of activity (Thompson, 1983) have been shown to affect the withdrawal of polyneuronal innervation, it is possible that asynchronous activation of the 2 motoncuron pools innervating a given muscle in Lamb's experiment (Lamb, 1981 b) would allow the persistence of synapses that would otherwise be withdrawn. In addition, other factors, such as interactions between motoneurons centrally, may need to be considered.

In summary, until more details are known about the quantitative relationships in dually innervated limbs during the cell death period, the study of Lamb, while intriguing, does not provide convincing evidence against a size-matching hypothesis. At the same time, while our results provide rather strong support for the size-matching hypothesis, until the bulk of motoneuron cell death can be prevented by increasing the size of the target, it will be necessary to consider that some neurons that die do so for reasons other than peripheral competition. The extent to which peripheral competition, in contrast to other factors such as afferent input and level of activity, affects cell death may vary greatly in different parts of the nervous system. Neuron cell death may also contribute to a sharpening of specific projections, although the original observations of Lamb made on Xenopus limbs of considerable numbers of projection errors that were removed during the cell death period (Lamb, 1976, 1979) have not been replicated in studies on Rana (Farel and Bemelmans, 1985).

Finally, even if one accepts some form of the size-matching hypothesis, one may wonder why neurons are overproduced in such large numbers. From an evolutionary point of view it has been speculated that an overproduction of neurons would allow for compensatory matching following either an increase or decrease in the size of the target (Katz and Lasek, 1978). Nevertheless, a survey of cell death in different species and different parts of the nervous system shows that in many cases the neuronal population is reduced by $40-60 \%$, apparently much more than would be needed to match the natural variation in target size. It was especially striking that in both the chick and the quail the pre-cell death number of motoneurons was almost exactly twice the final number, the percent of surviving motoneurons being $48.9 \%$ in the chick, and $50.5 \%$ in the quail.

It is possible that some aspect of the matching or innervation process simply requires this excess of neurons in order to insure that all target cells are innervated (see, for example, McLennan, $1983 \mathrm{~b}$ ). However, another possible explanation can be proposed (see also Hamburger and Oppenheim, 1982). This is more spec- ulative since we know little about the details of motoneuron proliferation (i.e., to what extent mitotic divisions are symmetrical, the length of the mitotic cycle, etc.) or how it is regulated. However, the modest variability in pre-cell death number of neurons indicates that proliferation is tightly regulated. In addition, the bulk of the 20,000 lumbar motoneurons in the chick are generated during a very short period, approximately 1.5-2 d (Hollyday and Hamburger, 1977). If one assumes that the lateral motor column is generated from a small number of precursor cells that each undergo a fixed number of symmetrical divisions, then if one began with 80 cells (i.e., 10 cells/approximately $100-\mu \mathrm{m}$-long segment), 6 divisions would produce 5120 cells, 7 divisions 10,240 cells, and 8 divisions 20,480 cells. Similarly, with 200 precursors, one would have values of 6400 , 12,800 , and 25,600 cells for these last 3 divisions. Thus, to ensure a moderate excess of cells to meet the demands of the target matching process, it may be necessary to generate approximately twice as many cells as required.

Another reason for a large excess of cells may be to compensate for slight temporal mismatches in the rate of development between cord and limb. Surprisingly, it was recently observed that, in the chick limb at the onset of cell death, most motoneurons have failed to penetrate very far into the developing muscle masses, and many growth cones are within major nerve branches (Tosney and Landmesser, 1985). Thus, if the onset of cell death occurs according to an innate schedule of the spinal cord, as our preliminary results indicate, many cells may enter their period of dependency on the periphery before being in a position to compete effectively for target-derived trophic factor and/or synaptic sites (see also Harris and McCaig, 1984). Any lag in limb development would greatly exaggerate this effect.

In conclusion, we have provided several pieces of evidence consistent with the quantitative matching hypothesis of cell death. Our results further suggest that some parameter that is proportional to the number of myotubes at the onset of cell death, such as the number of synaptic sites, may determine the number of neurons that will survive. However, a number of other factors may influence cell death, including afferent input, levels of activity, and even the appropriateness of connections; thus, in different parts of the nervous system, varying proportions of cells may die for each of these reasons.

\section{References}

Abercrombie, M. (1946) Estimation of nuclear population from microtome sections. Anat. Rec. 94: 239-247.

Arumugam, T., and G. S. Sohal (1985) Myotube clusters do not bear any quantitative relation to the extent of motoneuron survival. Exp. Neurol. 90: 281-286.

Betz, W. J., J. H. Caldwell, and R. R. Ribchester (1980) The effects of partial denervation at birth on the development of muscle fibers and motor units in rat lumbrical muscle. J. Physiol. (Lond.) 303:265279.

Boydston, W. R., and G. S. Sohal (1979) Grafting of additional periphery reduces embryonic loss of neurons. Brain Res. 178: 403-410.

Cowan, W. M. (1973) Neuronal death as a regulative mechanism in the control of cell number in the nervous system. In Development and Aging in the Nervous System. Academic, New York.

Cowan, W. M., J. W. Fawcett, D. D. M. O'Leary, and B. B. Stanfield (1984) Regressive events in neurogenesis. Science 225: 1258-1265.

Creazo, T. L., and G. S. Sohal (1979) Effects of chronic injections of (alpha)-bungarotoxin on embryonic cell death. Exp. Neurol. 66: 135145.

Cunningham, T. J. (1982) Naturally occurring neuron death and its regulation by developing neural pathways. Int. Rev. Cytol. 74: 163186.

Decker, R. S., and J. J. Kollros (1969) The effect of cold on hind-limb growth and lateral motor column development in Rana pipiens. $\mathrm{J}$. Embryol. Exp. Morphol. 21: 219-233.

Denton, C. J., A. H. Lamb, P. Wilson, and R. F. Mark (1985) Innervation pattern of muscles of one-legged Xenopus laevis supplied by 
motoneurons from both sides of the spinal cord. Dev. Brain Res. 17: 85-94.

Farel, P. B., and S. E. Bemelmans (1985) Specificity of motoneuron projection patterns during development of the bullfrog tadpole (Rana catesbiana). J. Comp. Neurol. 238: 128-134.

Guth, L., and I. J. Samaha (1970) Procedure for the histochemical demonstration of actinomyosin ATPase. Exp. Neurol. 28: 365-367.

Habgood, M. D., W. G. Hopkins, and J. R. Slack (1984) Muscle size and motor unit survival in mice. J. Physiol. (Lond.) 356: 303-314.

Hamburger, V. (1958) Regression versus peripheral control of differentiation in motor hypoplasia. Am. J. Anat. 102: 365-409.

Hamburger, V. (1975) Cell death in the development of the lateral motor column of the chick embryo. J. Comp. Neurol. 160: 535-546.

Hamburger, V., and H. Hamilton (1951) A series of normal stages in the development of the chick embryo. J. Morphol. 88: 49-92.

Hamburger, V., and R. W. Oppenheim (1982) Naturally occurring neuronal death in vertebrates. Neurosci. Comment. 1: 39-55.

Harris, A. J. (1981) Embryonic growth and innervation of rat skeletal muscles. I. Neural regulation of muscle fiber numbers. Philos. Trans. R. Soc. Lond. [Biol.] 293: 257-277.

Harris, A. J., and C. D. McCaig (1984) Motoneuron death and motor unit size during embryonic development of the rat. J. Neurosci. 4: 13-24.

Hollyday, M. (1981) Rules of motor innervation in chick embryos with supernumerary limbs. J. Comp. Neurol. 202: 439-465.

Iollyday, M. (1983) Development of motor innervation of chick limb. In Limb Development and Regeneration, Pt. A, J. F. Fallon and A. J. Caplan, eds., Alan R. Liss, New York.

Hollyday, M., and V. Hamburger (1976) Reduction of naturally occurring motor neuron loss by enlargement of the periphery. J. Comp. Neurol. 170: 311-320.

Hollyday, M., and V. Hamburger (1977) An autoradiographic study of the formation of the lateral motor column in the chick embryo. Brain Res. 132: 197-208.

Hollyday, M., and L. Mendell (1976) Analysis of moving supernumerary limbs of Xenopus laevis. Exp. Neurol. 51: 316-324.

Katz, M., and R. Lasek (1978) Evolution of the nervous system. Role of ontogenetic mechanisms in the evolution of matching populations. Proc. Natl. Acad. Sci. USA 75: 1349-1352.

Laing, N. G. (1982) Motor projection patterns in the hind limb of normal and paralysed chick embryos. J. Embryol. Exp. Morphol. 72: 269-286.

Lamb, A. H. (1976) The projection patterns of the ventral horn to the hind limb during development. Dev. Biol. 34: 82-99.

Lamb, A. H. (1979) Evidence that some developing limb motoneurons die for reasons other than peripheral competition. Dev. Biol. 71:821.

Lamb, A. H. (1980) Motoneurone counts in Xenopus frogs reared with one bilaterally innervated hindlimb. Nature 284:347-350.

Lamb, A. H. (1981a) Target dependency of developing motoneurons in Xenopus laevis. J. Comp. Neurol. 203: 157-171.

Lamb, A. H. (1981b) Selective bilateral motor innervation in Xenopus tadpoles with one hind limb. J. Embryol. Exp. Morphol. 65: 149163.

Lamb, A. H. (1984) Motoneuron death in the embryo. Crit. Rev. Clin. Neurobiol. 1: 141-179.

Lance-Jones, C. (1982) Motoneuron cell death in the developing lumbar spinal cord of the mouse. Dev. Brain Res. 4: 473-479.

Lance-Jones, C., and L. Landmesser (1981a) Pathway selection by chick lumbosacral motoneurons during normal development. Proc. R. Soc. Lond. [Biol.] 214: 1-18.

Lance-Jones, C., and L. Landmesser (1981b) Pathway selection by embryonic chick motoneurons in an experimentally altered environment. Proc. R. Soc. Lond. [Biol.] 214: 19-52.

Landmesser, L. (1978) The development of motor projection patterns in the chick hind limb. J. Physiol. (Lond.) 284: 391-414.

Landmesser, L., and M. O'Donovan (1984) The activation patterns of embryonic chick motoneurones projecting to inappropriate muscles. J. Physiol. (Lond.) 347: 205-224.

Landmesser, L., and G. Pilar (1974) Synapse formation during embryogenesis in ganglion cells lacking a periphery. J. Physiol. (Lond.) 241: 715-736.

Lanser, M. E., and J. F. Fallon (1984) Development of the lateral motor column in the limbless mutant chick embryo. J. Neurosci. 4: 2043-2050.
McLennan, I. S. (1982) Size of motoneuron pool may be related to number of myotubes in developing muscle. Dev. Biol. 92: 263-265.

McLennan, I. S. (1983a) Differentiation of muscle fiber types in the chicken hindlimb. Dev. Biol. 97: 222-228.

McLennan, I. S. (1983b) The development of the pattern of innervation in chicken hindlimb muscles: Evidence for specification of nerve-muscle connections. Dev. Biol. 97: 229-238.

McLennan, I. S. (1983c) Neural dependence and independence of myotubc production in chicken hindlimb muscles. Dev. Biol. 98 287-294.

Morris, D. G. (1978) Development of functional motor innervation in supernumerary hindlimbs of the chick embryo. J. Neurophysiol. 41: $1450-1465$

Narayanan, C. H., and Y. Narayanan (1978) Neuronal adjustments in developing nuclear centers of the chick embryo following transplantation of an additional optic primordium. J. Embryol. Exp. Morphol. 44: 53-70.

Nurcombe, V., M. A. Hill, K. L. Eagleson, and M. R. Bennett (1984) Motor neuron survival and neuritic extension from spinal cord explants induced by factors released from denervated muscle. Brain Res. 291: 19-28.

Okado, N., and R. W. Oppenheim (1984) Cell death of motoneurons on the chick embryo spinal cord. IX. The loss of motoneurons following removal of afferent inputs. J. Neurosci. 4: 1639-1652.

O'Leary, D. D. M., and W. M. Cowan (1984) Survival of isthmo-optic neurons after early removal of one eye. Dev. Brain Res. 12:293-310.

O'Leary, D. D. M., B. B. Stanfield, and W. M. Cowan (1981) Evidence that the early removal of the cells of origin of the callosal projection is due to the elimination of axonal collaterals rather than to the death of neurons. Dev. Brain Res. 1: 607-617.

Oppenheim, R. W. (1981) Neuronal cell death and some related regressive phenomena during neurogenesis. In Studies in Developmental Neurobiology: Essays in Honor of Viktor Hamburger, W. M. Cowan, ed., Oxford U.P., New York.

Oppenheim, R. W. (1984) Cell death of motoneurons in the chick embryo spinal cord. VIII. Motoneurons prevented from dying in the embryo persist after hatching. Dev. Biol. 101: 35-39.

Oppenheim, R. W., J.-W. Chu-Wang, and J. L. Maderdrut (1978) Cell death of motoneurons in the chick embryo spinal cord. III. The differentiation of motoneurons prior to their induced degeneration following limb-bud removal. J. Comp. Neurol. 177: 87-112.

Phillips, W. D., and M. R. Bennett (1984) Differentiation of fiber types in wing muscles during embryonic development: Effect of neural tube removal. Dev. Biol. 106: 457-468.

Pilar, G., L. Landmesser, and L. Burstein (1980) Competition for survival among developing ciliary ganglion cells. J. Neurophysiol. 43: 233-254.

Pittman, R., and R. W. Oppenheim (1978) Neuromuscular blockade increases motoneuron survival during normal cell death in the chick embryo. Nature 27 1: 364-366.

Pittman, R., and R. W. Oppenheim (1979) Ccll death of motoncurones in the chick embryo spinal cord. IV. Evidence that a functional neuromuscular interaction is involved in the regulation of naturally occurring cell death and the stabilization of synapses. J. Comp. Neurol. 187: 425-446.

Prestige, M. C. (1967) The control of cell number in the lumbar ventral horns during the development of Xenopus laevis tadpoles. J. Embryol. Exp. Morphol. 18: 359-387.

Smolen, A. J., I. I. Wright, and T. J. Cunningham (1983) Neuron numbers in the superior cervical sympathetic ganglion of the rat: A critical comparison of methods for cell counting. J. Neurocytol. 12. 739-750.

Sohal, G. S., and T. Yamashita (1985) Motoneuron survival following reduction in size of neuron pool. Soc. Neurosci. Abstr. 11: 258.

Sohal, G. S., T. S. Knox, J. C. Allen, T. Arumugam, L. R. Campbell, and T. Yamashita (1985) Development of the trochlear nucleus in quail and comparative study of the trochlear nucleus, nerve, and innervation of the superior oblique muscle in quail, chick, and duck. J. Comp. Neurol. 239: 227-236.

Sperry, D. G., and P. Grobstein (1985) Regulation of neuron numbers in Xenopus laevis: Effects of hormonal manipulation altering size at metamorphosis. J. Comp. Neurol. 232: 287-298.

Straznicky, C. (1983) The patterns of innervation and movements of ectopic hindlimb supplied by brachial spinal cord segments in the chick. Anat. Embryol. 167: 247-262. 
Summerbell, D., and R. V. Stirling (1981) The innervation of dorsoventrally reversed chick wings: Evidence that motor axons do not actively seek out their appropriate targets. J. Embryol. Exp. Morphol. 61: 233-247.

Tanaka, H., and L. Landmesser (1984) The quantitative matching hypothesis of neuronal cell death-A test using chick-quail chimeras. Soc. Neurosci. Abstr. 10: 186.7.

Tanaka, H., and L. Landmesser (1986) Interspecies selective motoneuron projection patterns in chick-quail chimcras. J. Neurosci. 6: $2880-2888$.

Tanaka, H., and K. Obata (1983) Survival of HRP-labeled spinal motoneurons of chick embryo in tissue and cell cultures. Dev. Brain Res. 9: 390-395.

Thoenen, H., and Y. Barde (1980) Physiology of nerve growth factor. Physiol. Rev. 60: 1284-1335.

Thompson, W. (1983) Synapse elimination in neonatal rat muscle is sensitive to pattern of muscle use. Nature 303: 614-616.
Thompson,W., D. P. Kuffler, and J. Jansen (1979) The effect of prolonged reversible block of nerve impulses on the elimination of polyneuronal innervation in newborn rat skeletal muscles. J. Neurosci. 4: $271-281$

Tosney, K, and L. Landmesser (1985) Specificity of motoneuron growth cone outgrowth in the chick hindlimb. J. Neurosci. 5: 2336-2344.

Tosney, K., M. Watanabe, L. Landmesser, and U. Rutishauser (1986) The distribution of NCAM in the chick hindlimb during axon outgrowth and synaptogencsis. Dev. Biol. 114: 437-452.

Weill, C. L., and D. P. Greene (1984) Prevention of natural motoneurone cell death by dibutryl cyclic GMP. Nature 308: 452-454.

Wetts, R., and K. Herrup (1983) Direct correlation between purkinje and granule cell number in the cerebella of lurcher chimeras and wildtype mice. Dev. Brain Res. 10:41-47. 